\title{
Alunos autistas: análise das possibilidades de interação social no contexto pedagógico
}

\author{
Alessandra Dilair Formagio Martins \\ Centro Universitário Nossa Senhora do Patrocínio- Itu - SP - Brasil \\ Maria Inês Bacellar Monteiro \\ Universidade Metodista de Piracicaba - Piracicaba - SP - Brasil
}

\begin{abstract}
Resumo
O estudo tem como tema os processos de significação vividos por sujeitos autistas nas interações sociais que estabelecem com os outros de seu grupo social, problematizando as interações sociais que envolvem a criança autista no contexto pedagógico de uma instituição voltada ao Transtorno do Espectro do Autismo. Trata-se de uma pesquisa empírica realizada por meio de vídeo-gravação da relação desses sujeitos com o professor e seus pares, que consistiu na observação de 20 episódios de atividades que implicam situações de aprendizado de um grupo de 4 crianças autistas com idades entre 6 e 10 anos, de uma sala de aula caracterizada como de Ensino Fundamental. As discussões e elaboração do material tiveram como base a análise microgenética, constatando possibilidades de desenvolvimento e aprendizado dos alunos autistas nas relações estabelecidas nesse contexto, aspecto que remete a discussão sobre as práticas utilizadas no tratamento desse transtorno que não favorecem as interações sociais.
\end{abstract}

Palavras-chave: Autismo; interação social; educação especial.

\section{Autistic students: analysis of the possibilities of social interaction in the pedagogical context}

\begin{abstract}
The study has as a theme the processes of signification experienced by autistic subjects in the social interactions they establish with others of their social group, problematizing the social interactions that involve the autistic child in the pedagogical context of an institution focused on Autism Spectrum Disorder. It is an empirical research carried out by means of video-recording of the relationship of these children with the teacher and his peers, which consisted in the observation of 20 episodes of activities involving learning situations of a group of 4 autistic children aged 6 And 10 years, of a classroom characterized as Elementary School. The discussions and preparation of the material were based on microgenetic analysis, confirming possibilities for the development and learning of autistic students in the relationships established in this context, an aspect that refers to the discussion about the practices used in the treatment of this disorder that do not favor social interactions.
\end{abstract}

Key words: Autism; social interaction; special education.

\section{Alumnos autistas: análisis de las posibilidades de interacción social en el contexto pedagógico}

\section{Resumen}

El estudio tiene como tema los procesos de significación vividos por sujetos autistas en las interacciones sociales que establecen conlos otros de su grupo social, problematizando las interacciones sociales que abarcan el niño autista en el contexto pedagógico de una institución volcada al Trastorno del Espectro del Autismo. Se trata de una investigación empírica basada en vídeo-grabación de la relación de esos sujetos con el profesor y sus pares, que consistióen la observación de 20 episodios de actividades que implican situaciones de aprendizaje de un grupo de 4 niños autistas con edades entre 6 y 10 años, de una sala de clase caracterizada como Enseñanza Primaria. Las discusiones y elaboración del material tuvieron como base el análisis microgenético, constatando posibilidades de desarrollo y aprendizaje de los alumnos autistas en las relaciones establecidas en ese contexto, aspecto que remete a la discusión sobre las prácticas utilizadas en el tratamiento de ese trastorno que no favorecen las interacciones sociales.

Palabras clave: Autismo; interacción social; educación especial. 


\section{Introdução}

O autismo foi descrito inicialmente em 1943, por Leo Kanner, um psiquiatra austríaco que apresentou onze casos de crianças (8 meninos e 3 meninas), com sintomas caracterizados basicamente pelo isolamento social, problemas na comunicação e movimentos estereotipados e repetitivos num artigo intitulado "Transtornos autísticos do contato afetivo"(Kanner, 1997).

Cerca de setenta anos, após a primeira descrição desse transtorno, várias foram as tentativas de explicá-lo nas mais diversas áreas do conhecimento e teorias, porém ainda não há um consenso em termos de delimitação de causas e intervenções eficazes, somente hipóteses.

Os estudos mais recentes sobre o transtorno encontram-se no campo das neurociências e genética que buscam encontrar alguma justificativa fisiológica ou fator genético que cause o autismo. Mas apesar das vastas pesquisas nesse campo, ainda não foi identificado qualquer fator específico que origine o transtorno. Sendo assim, as principais explicações correntes são as advindas das teorias afetivas, cognitivas e comportamentais.

Dentre as teorias afetivas a que apresenta maior destaque é a psicanálise, mas apesar de todas as propostas se embasarem na teoria freudiana, há divergências em termos da compreensão da estrutura psíquica dentre os diversos estudiosos dessa abordagem, destacando as teorias de Frances Tustin e Margaret Mahler que abordam a presença de um período na vida do bebê, logo após o nascimento, considerada Fase Autística Normal, em que o bebê cria uma membrana psíquica para proteger-se do excesso de estímulos e da angústia gerada por esses. Ao longo do processo de desenvolvimento, o bebê vai se adaptando melhor à realidade, a partir do vínculo estabelecido com a mãe, mas falhas nesse vínculo podem gerar uma estagnação nesse processo, gerando o autismo patológico. Por outro lado, a psicanálise lacaniana, cujos principais representantes no Brasil são Alfredo Jerusalinski e Maria Cristina Kupfer, explica a configuração do autismo a partir da falha na estruturação significante do psiquismo a partir do ingresso na estrutura da linguagem, desse modo, a criança autista não é visitada pelo desejo do outro, que investe libidinalmentena criança.

As teorias cognitivas, segundo Scheuer e Andrade (2007), podem auxiliar a compreender o funcionamento cognitivo e os comportamentos desse transtorno, embora não exista uma teoria específica que justifique ou explique o autismo. Até a década de 1970, as alterações cognitivas observadas nos casos de autismo não eram levadas em conta, por enfatizarem os aspectos sociais e emocionais relacionados ao transtorno. A partir desse período, constituíram-se dois grupos de pesquisadores para estudar o autismo, um grupo composto por Ornitz e Ritvoo qual considerava que as pessoas com autismo apresentavam um déficit primário no processamento perceptual e o outro composto por Rutter, Bartak, Newman e Churchill que focavam nos problemas de desenvolvimento e uso da linguagem (Scheuer \& Andrade, 2007)
Michael Rutter foi um dos primeiros pesquisadores a entender o autismo relacionado a uma desordem do desenvolvimento causada por um distúrbio do sistema nervoso central, inclusive salientando a importância de déficits cognitivos no autismo, relacionados à dificuldade no manejo das pistas sociais e emocionais. UttaFrith e Simon Baron-Cohen desenvolveram pesquisas relacionando à teoria cognitiva e o autismo e observaram que essas crianças apresentam dificuldade na atribuição de estados intencionais, ou seja, estados mentais com conteúdo ao outro(Scheuer \& Andrade, 2007).

Entre as principais ênfases da teoria cognitiva, a que tem se evidenciado no estudo desse transtorno é a Teoria da mente, apresentada entre 1989-1990 por Premack. Nesse referencial, entende-se que a mente é um conjunto de componentes programados de forma inata para "processar informações, para produzir conhecimentos e habilidades, pensamentos e sentimentos. A mente se desenvolve eseum componente falha, todos os demais são afetados" (Scheuer\& Andrade, 2007, p.87).

No caso do autismo é considerado que há uma incapacidade em desenvolver e conhecer a própria mente e a dos outros, aspecto que desencadeará um comprometimento em todas as áreas do desenvolvimento do sujeito.

A abordagem comportamental remete a um arcabouço teórico que nunca se constituiu como proposta para explicar o autismo, como nas teorias afetivas e cognitivas, mas sim propõe possibilidades de intervenções para o transtorno de base comportamental.

Fester e DeMyer na década de 60 foram os primeiros estudiosos a pesquisar o autismo a partir de um referencial comportamental. Esses estudos foram desenvolvidos em laboratório, observando os déficits comportamentais e os excessos associados ao transtorno tendo como causa os fatores ambientais (Rosenberg, 2011)

A partir dos estudos desenvolvidos no laboratório, esses autores estenderam suas pesquisas para o ambiente natural da criança, programas curriculares foram desenvolvidos e aperfeiçoados, visando ajudar os pais, familiares e a criança autista, principalmente no que relaciona-se à instalação, manutenção e generalização de comportamentos funcionais.

A nova versão do DSM 5 (APA, 2013) classifica o autismo como um "Transtorno do Espectro do Autismo", caracterizado, principalmente, por dificuldades na interação social, comunicação, movimentos estereotipados e repetitivos, com início até o término da infância.

Contemporaneamente, presenciamos as mais diversas formas de sintomas, que vão desde um comprometimento severo no desenvolvimento (fala ausente, grande dificuldade na interação, mesmo com familiares, hiperatividade, auto e hetero agressividade, etc.), até casos considerados mais "leves" (caracterizados por dificuldades na comunicação e interação social, porém que demonstram afeto às pessoas mais próximas, área cognitiva preservada, etc.) o que determina grande dificuldade na elaboração do diagnóstico. 
Atualmente, com as novas diretrizes curriculares e legislação dirigida para a inclusão das pessoas com necessidades educacionais especiais, observamos que os alunos autistasestão sendo inseridos nas escolas regulares. Até pouco tempo atrás, essas crianças frequentavam somente as instituições especiais e não havia um foco na escolarização, mas no desenvolvimento de habilidades cotidianas e extinção de comportamentos considerados inadequados.

Independente do aluno autista frequentar a escola regular, ou a instituição especial há em vigor um discurso sobre a escolarização dessas crianças, aspecto que demanda maior conhecimento sobre as relações estabelecidas entre os alunos com seus pares, equipe pedagógica e com outras instâncias institucionais, assim como reflexões sobre as possibilidades de ensinar esses alunos.

Um aspecto que deve ser ressaltado na educação do autista é justamente o significado que a aprendizagem tem para ele. Os sentidos produzidos a partir de suas ações e interações nas situações concretas vivenciadas nas diversas situações sociais vão constituir esse sujeito.

Vasques (2008) propõe que deveríamos repensar a educação dos autistas, deixando um pouco de lado paradigmas e padrões pré-estabelecidos e cristalizados da educação para pensar em ações pedagógicas que ajudem na negociação de sentidos e permitam ao aluno autista avançar em seu desenvolvimento.

Crianças autistas muitas vezes apresentam ações e discursos reduzidos ou que não são facilmente interpretados pelos outros (professores, mães, adultos ou pares). 0 que geralmente acontece é uma dificuldade muito grande em atribuir sentido às ações dessa criança, geralmente os outros entendem aquele comportamento como um ato sem significado.

É possível dar sentido às manifestações da criança autista? Como significar o mundo para ela? O que significa a não atribuição de sentidos para o desenvolvimento e aprendizagem de um aluno autista?

Tomando como base a teoria histórico-cultural, partimos do pressuposto de que é o outro que vai significar o mundo para a criança. Isto quer dizer que é através dos sentidos que os outros atribuem às ações da criança autista que tais ações ganham significado e passam a fazer parte de seu universo simbólico. Esta relação é de natureza dialética, isto é, a criança produz uma ação que é interpretada pelo "outro" e devolvida à criança que, por sua vez, passa a interpretá-la e aos poucos vai se construindo um sentido partilhado "eu-outro".

O conceito de mediação semiótica é descrito por Pino (1991) como central na obra de Vygotski, por constituir um conceito-chave relacionado a outros conceitos dessa teoria.

Pino (1991, p.33) considera "mediação toda intervenção de um terceiro "elemento" que possibilita a interação entre os "termos" de uma relação". O termo mediação tem a função de designar a inter-relação dos signos entre os sujeitos e a sociedade. O conceito de mediação foi desenvolvido por Vygotski, enfatizando a importância dos signos como instrumentos psicológicos produzidos pelo homem socialmente e utilizados por eles para comunicação e para se relacionar com o outro, com a cultura e com ele próprio.

Vygotski parte dessa premissa para reinterpretar o ato instrumental a partir da função da linguagem, fazendo disso o centro de seus estudos, utilizando o significado da palavra como norte para essa análise.

A análise do significado da palavra permitiu a Vygotski avançar na análise das relações entre pensamento e linguagem, considerando a linguagem como "um mediador funcional de situações interativas as mais diversas" (Pino, 1991, p.38).

Os signos são produzidos pelo próprio homem e, desse modo, pela história da humanidade. Apresentam como característica a reversibilidade que possibilita que adquiram um sentido para quem os emite e para quem os recebe, atribuindo diferentes sentidos a uma mesma vivência.

É através do processo de significação que o signo é apropriado pelo sujeito, o que significa que a relação com a realidade sempre é mediada pela cultura e pelo contexto histórico que está imerso. Através dos signos o sujeito se desenvolve, pois, ao mesmo tempo, que o sujeito transforma a realidade através da sua ação, ele também transforma a si mesmo se subjetivando.

Vygotski (1982) relata que desde o nascimento a criança constitui-se como um ser social e nesse sentido inverte a proposição de Goethe de que "no início foi a palavra" para "no início foi a ação", pois somente nas situações concretas de vida, na relação com um adulto, agindo, é que ocorre o aprendizado da linguagem e que esta adquire sentido.

A generalização é um processo muito importante na aquisição e desenvolvimento da linguagem, pois permite um aspecto considerado fundamental nesse processo que é a significação. A função significativa da palavra permite que se introduza um objeto, ao nomeá-lo, num sistema de conexões e relações que o analisa e o generaliza, possibilitando profundas transformações no desenvolvimento da criança. Nesse referencial, a palavra é caracterizada, conforme descrito por Smolka nos comentários da tradução da obra de Vygotski “Imaginação e criação na infância" (Smolka, 2009, 77) como produção humana que:

...viabiliza modos de interação (com os outros) e modos de operação mental (individual e intersubjetiva). A palavra possibilita ao homem indicar, nomear, referir, analisar; conhecer o mundo e conhecer-se. Pela linguagem o homem planeja e orienta as ações; por elas e com elas ele pode objetivar e construir a realidade.

A escola tem um papel fundamental no processo de significação, pois se constitui como o espaço de construção de significados e elaboração de sentidos de uma determinada cultura e contexto social.

A criança quando ingressa na escola passa a interagir com aspectos distintos do que estava habituada na relação com a família, esse ingresso é marcado por demandas, expectativas e rituais relacionados a esse novo espaço. A 
escola tem uma função específica que é a de instruir, trabaIhando o conhecimento historicamente produzido e possibilitando a participação da criança nesse processo histórico (Nogueira \& Smolka,2002).

A escola é vislumbrada, segundo ressaltam Nogueira e Smolka (2002, p.85) "como uma instituição social marcada por determinados modos de agir, de falar, que por sua vez delineiam e definem certos papéis e posições dos sujeitos envolvidos".

No caso das crianças com necessidades educacionais especiais a escola tem um papel fundamental, uma vez que os alunos com deficiência dependem das condições concretas oferecidas pelo grupo social que podem ser adequadas ou não, para o seu desenvolvimento. Conforme apontado por Vigotski (1997), não é o déficit em si que vai traçar o destino da criança, mas sim os modos como a deficiência é significada, como suas ações são interpretadas pelo outro e que experiências concretas the são oferecidas.

Alguns estudos recentes foram desenvolvidos ressaltando a importância da simbolização para o desenvolvimento das crianças com deficiências:Pinto (2004), Góes (2001), Padilha (2007), Huera, Souza, Melgaço e Tavares (2006), Souza e Batista (2008), Turetta (2013).

O aspecto nuclear do transtorno autista é a dificuldade em estabelecer relações interpessoais, o que na perspectiva histórico-cultural é considerado central para o desenvolvimento do sujeito. Contrastando com os programas desenvolvidos por outras perspectivas teóricas, as propostas fundamentadas nos estudos de Vigotski enfatizam a necessidade de investir nas possibilidades de interações sociais para garantir a superação das dificuldades de relacionamento com os outros do grupo social. Alguns estudos já têm apontado possibilidades de trabalhos com um olhar centrado nas interações, tais como,Bergo (1999), Bagarollo (2005), Orrú (2006, 2010), Passerino e Santarosa (2007), Martins (2009, 2013), Bragin (2011), Mattos e Nuemberg (2011), Chiote (2012). Cada um desses autores têm desenvolvido estudos específicos, mas que elegem como central a relação social estabelecida com o autista.

No estudo aqui apresentado, fundamentado nos pressupostos da perspectiva histórico-cultural, buscamos observar as interações sociais estabelecidas entre o aluno autista e seus pares, professora, monitora e pesquisadora, analisando os processos de significação, as possibilidades de desenvolvimento e escolarização desses sujeitos na escola regular.

A escolha de olhar para crianças autistas no contexto escolar, especificamente em situações que remetem ao aprendizado, justifica-se pelo fato de que é necessário compreender as relações produzidas nesse espaço, que ainda é novo no trabalho com o autista. O termo novo se relaciona à nova concepção de escola para esses alunos, caracterizada por espaços concretos de salas de aula, com uma rotina escolar organizada de forma similar a que é empregada para todas as crianças.

\section{Considerações metodológicas}

O estudo foi baseado na observação de uma sala de aula classificada como Ensino Fundamental ${ }^{1}$ de uma escola especial destinada ao atendimento de alunos com Transtornos do Espectro do Autismo. A sala de aula era composta por quatro alunos, três meninos e uma menina, com diagnóstico de autismo e idade entre 6 a 10 anos $^{2}$. As análises apresentadas referem-se a 20 filmagens, com cerca de 1 hora, que ocorreram durante todo o período do ano letivo de forma semanal, em dias e horários alternados da semana, a fim de destacar várias atividades.

Nos primeiros contatos a pesquisadora só realizou observação, priorizando a adaptação junto aos alunos e após a terceira semana de contato, iniciou com as filmagens sendo bem recebida pela equipe e crianças, que demonstraram grande interesse pela câmera. Os alunos que participaram da pesquisa foram os seguintes:

1. Luís: Diagnóstico segundo CID 10, F84 - Autismo. Idade de 6 anos, bastante agitado. A fala mostra-se ausente.

2. Ana: Diagnóstico segundo CID 10, F84 - Autismo e F71Deficiência mental leve. Idade de 8 anos, a fala está preservada, mas sempre se mostra num tom muito baixo, quase inaudível.

3. Pedro: Diagnóstico segundo CID 10, F84 - Autismo e F79 - Deficiência mental. Idade de 8 anos, mostra-se calmo, porém com episódios de agitação motora, a fala está preservada, mas ecolálica.

4. Daniel: Diagnóstico segundo CID 10, F84 - Autismo e F71Deficiência mental leve. Idade de 10 anos, bastante agitado, a fala está comprometida, fala poucas palavras, geralmente repetição.

As filmagens foram transcritas de forma detalhada em diário de campo, buscando identificar processos interativos dos alunos autistas com seus pares, professora e monitora, analisados a partir da análise microgenética, método que tem como base o paradigma indiciário descrito por Carlo Ginzburg (1989).Góes (2000, pp.9-10) ao descrever esta forma de análise afirma que:

...De um modo geral trata-se de uma forma de construção de dados que requer a atenção a detalhes e o recorte de episódios interativos, sendo o exame orientado para o funcionamento dos sujeitos focais, as relações intersubjetivas e as condições sociais da situação, resultando num relato minucioso dos acontecimentos. Frequentemente, dadas as demandas de registro implicadas, essa análise é associada ao uso de vídeo-gravação, envolvendo o domínio de

1 Classificação feita pela própria instituição, a partir de critérios como: idade e nível de desenvolvimento global da criança.

2 Os nomes das crianças foram alterados para preservar a identidade das mesmas. 
estratégias para a filmagem e a trabalhosa atividade de transcrição.

Tal procedimento permitiu identificar minúcias dos processos interativos de alunos autistas em situações de ensino, que geralmente são pouco perceptíveis numa observação mais ampla.

\section{Resultados e discussão}

Para compreender como as interações sociais estabelecidas entre o aluno autista e seus pares, professora, monitora e pesquisadora ocorreram nas situações de ensino, serão apresentados a seguir episódios selecionados de todo o material registrado, organizados com base em três referências: A) A interpretação da ação do aluno autista; B) As mediações sociais e os indícios de processos de significação; C) A orientação do autista para o outro.

\section{A complexidade na interpretação da ação do aluno autista}

A interpretação das ações do aluno autista pela professora ganha uma dimensão maior se considerarmos que é na relação com o outro que as ações da criança vão ganhar sentido e passar a fazer parte de seu universo simbólico. Muitas das manifestações de crianças autistas podem causar estranheza para seus interlocutores, que ficam confusos em relação a como responder para construir um sentido partilhado com o outro. O episódio a seguir revela a complexidade desta relação:

Luís anda pela sala. A professora estava sentada junto à sua mesa fazendo anotações na agenda dos alunos, levanta-se de sua cadeira, pega Luís pela mão e o conduz até a cadeira, colocando-o sentado, mas ele recomeça a andar. Luís tenta subir na cadeira da professora, ela dirigese a ele, impedindo-o e conduzindo Luís até sua carteira.

Profa.: "Olha sua cadeira aqui!" (A professora fala brava.)

A professora aponta para uma ficha de identificação com foto de Luís que está sobre a mesa. Ele olha rapidamente, mas desvia o olhar.

Profa.: "Quem é aqui? Quem é? Luís! Olha aqui o Luís, cadê o abraço da professora?" (A professora dirige-se à ele falando pausadamente)

A professora aproxima-se de Luís e abraça-o, para à sua frente, Luís a encara, apertando suas bochechas com as duas mãos diversas vezes, rindo. Luís aproxima-se mais da professora, beijando-a no rosto e a abraça com força. A professora retribui o abraço, ele a abraça e beija novamente.

Luís olha para a professora sorrindo e aperta sua bochecha, como se a acariciasse. A professora brinca com a mão de Luís, como se a estivesse mordendo levemente, ele aproxima o rosto dela, roçando a mão em seu rosto e em seu peito, aninhando-se. Ele aperta a bochecha da professora, ela aperta sua bochecha, Luís aperta a bochecha da professora novamente, intensificando a força, ri e aperta com mais força, ela afasta sua mão, aparentando irritação, ele continua a rir.

Profa.: "Pára!" (A professora fala brava.)

A professora levanta-se e afasta-se.

No episódio descrito acima, a professora aproxima-se de Luís para retirá-lo de cima da cadeira e o conduz até sua carteira, explicando com auxílio da ficha de identificação onde deveria sentar-se. Luís reage afetuosamente apertando delicadamente a bochecha da professora, abraçando-a, beijando-a e se aninhando, mas quando ele aperta com mais força a bochecha da professora e ri, ela o repreende e afasta-se. O comportamento inesperado de Luís provoca uma reação de afastamento da professora. Fica difícil para ela interpretar a ação da criança, ao mesmo tempo em que ele a acaricia e a agride em seguida. Esse é um fenômeno comum na relação com os autistas, quando não respondem conforme o esperado as pessoas em torno tendem a desistir da interação, por não encontrar sentido na sua resposta.

O comportamento esperado pela professora era da troca lúdica/ afetiva no ato de apertar a bochecha, repetindo seu próprio gesto, porém quando Luis aperta com muita força, algo que foge à resposta aguardada pela professora, ela fica irritada e se afasta, por não compreender sua ação, ou seja, a resposta adversa.

A professora ao afastar-se procura mostrar sua insatisfação face à ação de Luís e a troca de afetos inicial, tão desejada e descrita como rara em crianças autistas, deixa de ser partilhada, a ruptura dessa cadeia associativa remete à falta de atribuição de sentidos da professora ao comportamento da criança, por fugir da reação esperada para aquele evento, comportamento que poderia ser significado focando a resposta real e não desejada da criança auxiliando na relação entre o par, segundo Smolka (2010, p.116):

\footnotetext{
...a sensibilidade orgânica e as sensações vão se tornando significativas, na medida em que os corpos/sujeitos se afetam e produzem efeitos/afetos uns nos outros; as emoções vão se (trans)formando e os sentimentos vão sendo forjados, relacionados à possibilidade de significação (produção de signos na relação) e constituição do funcionamento mental e do conhecimento pela linguagem (lógica, razão - logos); as direções e orientações das (inter)ações significam relacionadas ao movimento, situação e posições dos sujeitos no espaço e no tempo (história).
}

Nesse episódio, as posições sociais (professora/aluno) ocupadas pelos envolvidos na atividade constituem um aspecto que interfere na expectativa de resposta, pois a pro- 
fessora parece aguardar uma reação de afeto positiva, pela invocação de uma atitude de auxílio ao aluno, denotando seu lugar de professor que ensina e que convencionalmente espera reconhecimento. A professora não busca compreender o sentido que Luis apreendeu dessa relação e se ele tem clareza dessa expectativa e de como responder a essa interação.

A dificuldade na compreensão das respostas da criança autista é observada nas diversas relações que a criança está inserida, com os familiares, profissionais da equipe multidisciplinar que o atende, sempre voltada à expectativa de respostas específicas a um determinado comportamento, e quando a criança não responde aos estímulos solicitados, ao analisar mais detidamente, muitas vezes não evidenciamos uma falta de resposta, mas uma resposta diferente da aguardada.

Nesse sentido, o foco do trabalho com o autista não deveria analisar se responde adequadamente ao esperado, mas na observação das reações ou indícios das respostas apresentadas pelo autista, focando nos sentidos elaborados a partir da experiência da criança que poderão ser mais explorados e estruturados.

\section{As mediações sociais e os indícios de processos de significação}

A criança autista geralmente é olhada a partir daquilo que a identifica como autista, ou seja, a partir daquilo que não consegue fazer. Muito pouco foi dito sobre suas possibilidades e sobre como interagir com elas. O estudo demarca a importância do papel do outro, no desenvolvimento das funções psíquicas superiores, através da atuação da professora junto a esses alunos, auxiliando e orientando suas ações, relações que estão sendo desenvolvidas, principalmente no que se refere à produção e elaboração de sentidos por parte dos alunos e da própria professora que muitas vezes surpreende-se com as respostas e reações dos alunos. O episódio a seguir ilustra esses aspectos:

A professora aproxima-se de Pedro que está sentado em sua carteira, Ihe entrega uma folha de atividade em que ele deverá parear figuras de animais iguais.

Profa.: "Pedro, você vai parear os animais iguais, mas os menores." (A professora explica pausadamente, mostrandose tranquila).

Pedro olha para a folha de atividade entregue pela professora e aponta a figura de um leão, com a juba grande parecendo um sol.

Pedro: "O sol?"

Profa.: "Sol não, é um animal!" (A professora fala em tom sério)
Pedro: "O sol?"

Profa.: "O sol não! O sol é um animal?" (A professora o questiona repreendendo-o)

Pedro: "É um lobo mau, au, argh!" (A juba do leão se assemelha a raios solares, pintada na cor amarela).

Profa.: “É um leão! Leão é um animal selvagem!" (A professora fala em tom sério, mas pausadamente).

Pedro olha sério para a professora e depois para a atividade, pega a carta com a figura de leão e a coloca ao lado da figura do leão.

Profa.: "Qual é o maior? Qual é o leão maior?"

Pedro aponta a figura maior.

Profa.: "Isso!"

Pedro pareia as outras figuras, aponta para uma delas com a figura de um gato.

Profa.: "É um gatinho! Qual o menor, qual é?"

Pedro: Pedro aponta para a figura maior. "É esse daí!"

Profa.: A professora aponta para figura maior "Esse é o maior e o menor, qual é?" (A professora pergunta novamente).

Pedro aponta para figura maior e olha atento.

Profa.: "E o menor, o gato menor, qual é?"

A professora aponta para figura menor, Pedro olha, mas dispersa a atenção olhando para sua frente.

Profa.: "Pedro, qual é o leão menor?" (A professora fala em tom sério)

Pedro: "Argh!"

Pedro desvia a atenção, a professora guarda a atividade, fechando a cara, mostrando-se irritada se afasta.

No episódio quando a professora apresenta uma figura de leão à Pedro, ele responde atribuindo um significado diferente do esperado para a figura, dizendo que é "um sol", a professora discorda questionando se "o sol é um animal", ele associa a imagem do animal ao lobo mal, inclusive rugindo, mas a professora enfatiza que é um leão. A rede de significados é interrompida, para dar continuidade à atividade proposta, por meio da resposta que era esperada para a mesma.

Pedro continua atento aos dizeres da professora e à execução da atividade. Inicialmente Pedro responde cor- 
retamente à solicitação da professora ao apontar a figura maior questionada por ela, mas ao mostrar outra figura em que deveria apontar a menor, ele erra apontando a maior, a professora responde explicando que a figura do gato era a menor, mesmo com a insistência da professora, Pedro dispersa a atenção, e ao rosnar para ela, busca retomar a rede de significados instaurada anteriormente, a professora novamente o interrompe e ele se afasta.

Parece que os sentidos que diferem do que é esperado para a proposta da atividade interferem na relação estabelecida com a professora, dando a impressão de que a criança não compreendeu a atividade, porém outras possibilidades de interpretação e intervenção são engendradas a partir dos novos sentidos que a criança propôs para a atividade, baseados em suas experiências anteriores, mas os quais não são ampliados por não pertencerem ao objetivo inicialmente esperado, ou seja, a resposta correta.

Apesar da interpretação truncada da professora dos sentidos elaborados por Pedro, cabe destacar o movimento de Pedro ao propor sentidos para a figura, baseado em suas vivências, buscando tentar compreender o que a atividade apontava Nogueira e Smolka (2002, p.90) ressaltam que:

... imersas nas práticas cotidianas, as crianças vão experimentando diferentes relações e posições. $\mathrm{Na}$ dinâmica das interlocuções, os sentidos não se produzem apenas pelas intenções individuais, mas são resultantes das condições de produção, do jogo das relações, da posição ocupada pelos interlocutores.

No episódio a experiência anterior da criança parece que é desconsiderada com uma ênfase na resposta esperada para atividade, destacando as posições que professor e aluno ocupam nessa relação. A criança continua participando de sua elaboração, tentando compreendê-la, mas é observado um descompasso das respostas de Pedro em relação às perguntas da professora como um fator que parece dificultar a elaboração de sentidos, pois ao "errar" a resposta, referindo algo fora do contexto previamente esperado para a atividade, tendo o foco da atividade voltada ao produto final, ou seja, à resposta esperada e não ao processo de construção de sentidos que poderia ser compartilhado a partir da relação entre professor aluno, é reduzida a possibilidade de inúmeros significados que essa experiência poderia ter engendrado.

\section{O autista orienta-se ao outro}

É importante destacar o movimento da criança autista de dirigir-se ao outro, aspecto que destoa um pouco das classificações sobre as características do autista que evidenciam um comprometimento da interação social recíproca, ou seja, de focar a atenção ao outro.

As crianças observadas, além dos graves comprometimentos no comportamento que não podem deixar de ser destacados, têm uma maneira peculiar de interagir, porém em diversas ocasiões foi observado um movimento de busca de contato com o outro, mesmo que de forma rápida e algumas vezes implícita, com um gesto ou um olhar, mostrando inclusive compreender a atitude do outro e expressões de sentimento ao outro. Cabe destacar nesses episódios o papel das interações sociais no desenvolvimento da criança autista e as possibilidades de desenvolvimento engendradas a partir dessas inter(ações). O episódio exposto a seguir demonstra esse aspecto:

O episódio corresponde à primeira sessão vídeo-gravada, especificamente após cerca de uma hora após ter sido iniciada a filmagem. As crianças acabam de retornar do lanche, Luís está andando pela sala, Ana, Daniel e Pedro estão sentados na cadeira junto à carteira. A professora inicia uma atividade, auxiliando Ana na leitura da letra de uma música sobre "índios", apresentada numa folha que Ana anteriormente pintou com cola colorida, o desenho representava índios num bote.

Pedro levanta-se e se aproxima da filmadora, observando de relance.

Pesq.: "Pedro quer vir aqui ver a câmera?"

Ele aproxima-se, a pesquisadora mostra-lhe o visor, aparece a imagem de Ana e da professora Marta, que olha na direção da pesquisadora sorrindo.

Pesq.: "Olha lá a Ana fazendo atividade."

Pedro: "Tia Marta!"

Pesq.: "Olha lá a Ana! Está fazendo a atividade ali também, você viu?"

Pedro: "Ana!"

Pesq.: "A Ana está fazendo a atividade, você viu?"

Pedro: "Tia Marta também!" (Ele ri alto.)

Pesq.: "Você também pode aparecer na televisãozinha aqui, também. Quer sentar na sua carteira para eu filmar você também?" (Pedro novamente ri alto.)

Pedro dirige-se até sua carteira sentando-se, olha e sorri para câmera. Permaneceu ali sentado, cantando a música dos indiozinhos relacionada à atividade realizada anteriormente, deita o rosto encostando-o na mesa, e começa a bater a palma da mão na mesa, olhando atento para câmera.

Pesq.: "Olha só o Pedro!" (A pesquisadora diz sorrindo)

Pedro logo desvia o olhar da câmera acompanhando o movimento da professora que se afasta em direção a 
Daniel que começa a correr pela sala. Após um período em que realizava atividade, Ana levanta-se e se aproxima da pesquisadora com os braços abertos, sorrindo e abraçando a pesquisadora.

Pesq.: "Um abraço! Que abraço bom!" (A pesquisadora fala, mostrando-se alegre com o abraço)

Ana fica ali abraçada com a pesquisadora, sorri, observando o visor da câmera por um curto período, depois volta e sentase na sua cadeira. (Anteriormente Ana observava o visor da filmadora, enquanto a pesquisadora aponta nomeando os colegas que ela via).

Nessa situação, inicialmente Pedro observa a filmadora de longe, mas convidado pela pesquisadora, responde dirigindo-se até ela, interessando-se pela filmadora e, ao olhar pelo visor, identifica as pessoas que visualiza, nomeando-as, a pesquisadora enfatiza esses sentidos atribuídos pela criança, contextualizando as imagens vistas no visor da câmera, ele contribui atribuindo outras associações a respeito. Ao retornar à carteira a pedido da pesquisadora, para também ser filmado, ele opta por isso, Pedro acena para câmera demonstrando querer ser filmado, o que revela ter compreendido o pedido da pesquisadora. Ao perceber esse movimento, Ana, após encerrar a atividade, também se dirige até a pesquisadora olhando o visor da câmera e mostra interesse pelo equipamento e pela pesquisadora, ao abraçá-la e ao permanecer ali naquela posição observando o visor, enquanto a pesquisadora nomeava o que era visto.

$\mathrm{O}$ interesse pela filmagem foi um aspecto muito evidenciado durante as observações, todas as crianças em algum momento, alguns mais, outros menos, manifestaram algum interesse em olhar o visor da mesma, muitas vezes até mostrando-se agitados. Houve momentos que a pesquisadora percebeu que algumas das crianças "faziam graça" para a câmera, seja acenando, sorrindo, olhando fixamente para ela. Vários sentidos foram produzidos nessa relação entre a criança, a pesquisadora e o objeto.

A curiosidade pela câmera e pelo que/quem estava sendo filmado, despertou o interesse das crianças em buscar o outro, atestando a atenção das crianças autistas ao que ocorre ao seu redor, inclusive às alterações do contexto imediato, assim como a sua iniciativa ao buscar ou destacar o que lhe despertou interesse. Chiote (2012, p.16) enfatiza que:

Acreditamos que, diante da criança com autismo e suas especificidades, assim como qualquer criança, as possibilidades de desenvolvimento não estão predeterminadas; elas são criadas nas situações concretas em que suas potencialidades se manifestam de alguma forma, nos processos interativos.

Cabe destacar nesse episódio a importância da situação concreta que permite novas aprendizagens. A situação concreta é a filmadora e a pesquisadora filmando e o novo é a compreensão da possibilidade de se ver na filmagem. $\mathrm{O}$ interesse pela filmagem nasce de algo concreto e ver a si mesma, colegas e professora na imagem filmada confere um novo sentido para a ação. Os alunos até fazem graça sorrindo, acenando, ou olhando fixamente para a câmara, o que possibilita refletir sobre a possibilidade da produção de novos sentidos a partir das situações concretas e experiências vivenciadas pelo autista na relação com o outro.

Importante destacar nesse episódio que a resposta positiva e esperada da criança autista, diante de uma determinada atividade, parece auxiliar na receptividade do outro na relação, aspecto que denota uma reflexão acerca das relações que são estabelecidas com a criança autista. Parece que essa falta de retorno, de interesse pelo outro, interfere na forma como as outras pessoas organizam seu modo de agir com esses sujeitos, pois quando não identificam um retorno de respostas na relação com o autista, gera frustração e consequente desinteresse e distanciamento, aspectos presentes de forma muito constante na atuação da equipe e nas relações familiares com esses sujeitos.

\section{Considerações finais}

O autismo não foi um transtorno estudado por Vygotski, o autor faleceu em 1934 e os primeiros relatos difundidos por Leo Kanner sobre os "Transtornos do Espectro Autista" datam do ano de 1943. Apesar disso, as proposições teóricas do autor mostram-se bastante pertinentes ao estudo sobre o distúrbio, principalmente no que remete às possibilidades de desenvolvimento da criança deficiente, a partir das relações sociais estabelecidas com as pessoas ao seu entorno. Esse estudo não visa contemplar toda a discussão sobre o tema, mas possibilitar que a partir dele outras possibilidades de reflexão sejam engendradas.

Ao olharmos para o desenvolvimento e educação de alunos autistas temos que considerar a relevância das relações sociais e de sua interação com os outros com os quais convivem. Apesar dos descritos comprometimentos quanto à interação do autista com o outro, a ênfase nas relações sociais pode apresentar-se como a chave que possibilita o desenvolvimento desses sujeitos, pois para Vygotski (1996, p.285) "a relação da criança, com a realidade circundante, é social, desde o princípio. Desse ponto de vista, podemos definir o bebê como um ser maximamente social".

Deslocar o foco dos estudos sobre autistas para a relação significa olhar não mais para as dificuldades do sujeito em si, mas para como suas ações são interpretadas/ significadas pelos outros e para os caminhos diversos que permitam a superação das dificuldades iniciais.

A professora em diversas situações interpreta as ações das crianças construindo sentidos compartilhados. Entretanto, também se tornam evidentes as dificuldades quando em algumas situações a interpretação fica truncada diante de ações inesperadas dos alunos e a expectativa de uma resposta padrão quando não ocorre ou difere da forma 
esperada pela professora. Esta dificuldade não é só da professora, mas relatada por muitos pais e profissionais que convivem com o autista.

Quando essas situações ocorrem na sala de aula, a professora tende a retomar algo mais organizado e compreensível para ela, relacionado ao objetivo esperado para uma determinada atividade pedagógica, insistindo em concluí-la.

A criança autista geralmente é vista com uma série de impossibilidades determinadas pelas peculiaridades em seu comportamento e muito pouco foi dito sobre possibilidades de atuar junto a esses sujeitos, promovendo interações com os mesmos. As propostas educacionais focam métodos específicos que tendem a valorizar a execução de tarefas, a inibição de ações consideradas indesejáveis ou incompreensíveis, geralmente não valorizando a interação social e a abstração.

Não é considerado fácil identificar ou compreender muitos dos comportamentos e sentidos produzidos e atribuídos pelo autista na interação com o outro, pois muitas vezes diferem do que é considerado como habitual e até são considerados pouco ou não inteligíveis, se comparados ao que se espera numa relação interpessoal, aspecto que dificulta muito as relações com a criança autista, mas deveriamser valorizadas e enfatizadas as interações desses sujeitos, mesmo que mínimas e a busca da compreensão dos sentidos produzidos a partir destas.

É importante destacar que em diversos contextos é possível observar nuances de tentativas de articulação de sentidos, da inserção dessas crianças no contexto social propiciado, inclusive cultural, pois as crianças em diversos momentos agem a partir de referenciais que não estão somente presentes no contexto imediato, mas que se ampliam para o contexto familiar e cultural, atribuindo sentidos a figuras e coisas, com base em experiências que já tiveram anteriormente.

O que escapa ao que se é esperado na produção dos sentidos deveria ser o núcleo de investimento na relação com o sujeito com esse transtorno, ou seja, nas possibilidades de produção de algum sentido, mesmo que não condizente ao contexto, pois a partir disso, o autista pode tentar ser compreendido a partir do sentido instaurado por ele, introduzindo-o na situação de aprendizado.

A resposta a essas tentativas de interação nem sempre é manifestada de forma positiva pela criança, mas pode ocorrer de forma negativa, demarcada muitas vezes com demonstração de aborrecimento, ou acarretando um desinteresse destas pela continuidade em algumas atividades, o problema com essa resposta negativa, ou fora de contexto é que tende a gerar frustração e afastamento do outro, por não sentir-se compreendido pelo autista, identificando como desinteresse da criança, ou sintoma do transtorno.

O trabalho atual com autistas, baseados em visões organicistas e comportamentais tem evidenciado técnicas mais estruturadas que não vislumbram possibilidades de interação mais efetivas com esses sujeitos, ao contrário, muitas vezes acabam ocasionando maior distanciamento e a escola que muitas vezes não sabe como lidar com essa clientela, pois a escolarização de autistas ainda é um pro- cesso novo, acaba perpetuando essas concepções e consequentemente essa forma de distanciamento.

A educação, desse modo, deve assumir o papel de uma elevação num caminho anteriormente visto como plano, alavancando o desenvolvimento da criança, principalmente nos casos de crianças com qualquer deficiência, como no caso do autismo,no qual o papel da educação deverá ser mais atuante, pois a criança necessitará de um auxílio e envolvimento mais efetivo do outro.

A significação atua como uma chave para tentar compreender a conversão das relações sociais em funções mentais. Nogueira e Smolka (2002, p.83) enfatizam que "é na emergência da significação, enquanto signos e sentidos, que viabiliza um novo princípio, ao mesmo tempo regulador da conduta e gerador de novas formas de atividade".

A significação é o que irá conferir ao social sua condição humana, o que nos leva a pensar segundo afirma Pino (2000, p.59, grifo do autor) que "a convivência humana é regida por leis históricas, e não por mecanismos mentais ou biológicos".

Os significados são produzidos a partir das relações, tendo como base as experiências prévias dos sujeitos envolvidos, desse modo, o aprendizado da criança autista não pode continuar ocorrendo a partir da concepção de que esses sujeitos são destituídos de qualquer conhecimento ou experiência, mas enfatizando o que já vivenciaram e os sentidos produzidos a partir desse conhecimento, mesmo que não seja coerente com o que é esperado, só buscando compreender essas crianças e organizando o processo de aprendizado a partir dessa interação é possível pensar numa relação em que sentidos sejam produzidos e significados.

\section{Referências bibliográficas}

American Psychiatric Association [APA] (2013). DSM-5, Manual diagnóstico e estatístico de transtornos mentais. Porto Alegre: Artmed.

Bagarollo, M. F. (2005). A re(significação do brincar das crianças autistas, Dissertação de Mestrado, Universidade Metodista de Piracicaba, Piracicaba, SP.

Bergo, M. S. A. A. (1999). Uma visão da Síndrome de Asperger sob o enfoque de Vygotsky. Revista Brasileira de Educação Especial, 5.

Bragin, J. M. B. (2011)Atividades educacionais para autistas na escola especial. Dissertação de Mestrado, Universidade Metodista de Piracicaba. Piracicaba, SP.

Chiote, F. A. B. (2012). A mediação pedagógica no desenvolvimento do brincar da criança com autismo na educação infantil, Trabalho apresentado na $35^{\circ}$ Reunião Anual da ANPEd, GT 15: Educação especial, Porto de Galinhas, PE.

Ginzburg, C. (1989). Mitos, Emblemas, sinais(Carotti, Trad.). São Paulo: Companhia das Letras. 
Góes, M. C. R. (2000). A abordagem microgenética na matriz histórico-cultural: uma perspectiva para o estudo da constituição da subjetividade.Cadernos Cedes, 20 (50), 157-171.

Góes, M. C. R. (2001).O brincar de crianças surdas: examinando a linguagem no jogo imaginário, Trabalho apresentado na $24^{\circ}$ Reunião Anual da ANPEd.

Huera, L., Souza, C. M.L. Batista, C. G. Melgaço, M. B., \& Tavares, F. S. (2006). O faz-de-conta em crianças com deficiência visual: Identificando habilidades. Revista Brasileira de Educação Especial,12(3), 351-368.

Kanner, L. (1997). Os distúrbios autísticos do contato afetivo. Em P. S. Rocha (Org.). Autismos, São Paulo: Escuta, 111-170.

Martins, A. D. F. (2009). Crianças autistas em situação de brincadeira: apontamentos para as práticas educativas, Dissertação de Mestrado, Universidade Metodista de Piracicaba, Piracicaba, SP.

Martins, A. D. F. (2013) Processos de significação e o aluno autista, Tese de Doutorado em Educação). Universidade Metodista de Piracicaba, Piracicaba, SP.

Mattos, L. K. \& Nuemberg, A. H. (2011). Reflexões sobre a inclusão escolar de uma criança com diagnóstico de autismo na educação infantil.Revista Brasileira Educação Especial, 24 (39), 129-142.

Nogueira, A. L. H. \& Smolka, A. L. B. (2002).O desenvolvimento cultural da criança: mediação, dialogia e inter(regulação). Em M. K. Oliveira, T. C. Rego \& D. T. Souza (Orgs.),Psicologia educação e as temáticas da vida contemporânea, São Paulo: Moderna, 77-94.

Orrú, S. E. (2006)A constituição da linguagem de alunos autistas apoiada em comunicação suplementar alternativa. Tese de Doutorado.Universidade Metodista de Piracicaba. Piracicaba-SP.

Orrú, S. E. (2010). Contribuições da abordagem histórico-cultural na educação de alunos autistas, Humanidades Médicas, v.10, n.3, Sep-Dec.

Pino, A. (1991). O conceito de mediação semiótica em Vygotsky e seu papel na explicação do psiquismo humano. Cadernos Cedes 24 Pensamento e Linguagem: estudos na perspectiva da psicologia soviética, Campinas: Papirus, Março/Julho, 32-43.
Pino, A. (2000). O social e o cultural na obra de Vigotski. Educação e Sociedade, ano XXI, $n^{\circ} 71$, Julho.

Padilha, A. M. L. (2007). Práticas pedagógicas na educação especial: a capacidade de significar o mundo e a inserção cultural do deficiente mental. $3^{\circ}$ Edição. Autores Associados: Campinas-SP.

Passerino, L. M. Santarosa, L. C.(2007). Interação social no autismo em ambientes digitais de aprendizagem.Psicologia: Reflexão e crítica, 20 (1), 54-64.

Pinto, G. U.(2004).O brincar na infância: um estudo em instituição especial para deficientes mentais. Dissertação de Mestrado. Universidade Metodista de Piracicaba, Piracicaba-SP.

Rosenberg, R. (2001). História do autismo no mundo. Em J. S. Schwartzman \& C. A. Araújo(Orgs.).Transtornos do Espectro do Autismo. São Paulo: Memnon.

Scheuer, C. I. \&Andrade, R. V. (2007). Teorias cognitivas e autismo. EmF. A. J. Assumpção \& E. Kuczynski (Orgs.).Autismo infantil: novas tendências e perspectivas. São Paulo: Atheneu.

Smolka, A. L. B. (2010). Ensinar e significar: as relações de ensino em questão ou das (não) coincidências nas relações de ensino. Em A. L. H. Nogueira \& A. L. B. Smolka (Orgs.), Questões de desenvolvimento humano: práticas e sentidos, São Paulo: Mercado das Letras, 107-128.

Smolka, A. L. (2009). Apresentação e comentários. Em L. S. Vigotski. Imaginação e criação na infância, Tradução Zoia Prestes, São Paulo: Ática, 77.

Vasques, C. K. (2008). Transtornos Globais do Desenvolvimento e Educação: Análise da Produção Científico-Acadêmica,Trabalho apresentado na $31^{\circ}$ Reunião Anual da ANPED, GT-15: Educação Especial, Caxambu.

Vygotski, L. S. (1982) Obras Escogidas, II, Ed. Visor: Madri.

Vygotski, L. S. (1996). Obras Escogidas IV, Madri: Visor.

Vygotski, L. S. (1997). Obras Escogidas V: fundamentos de defectología, Madrid: Visor.

Recebido em: 03 de fevereiro de 2016 Aprovado em: 29 de novembro de 2016

\section{Sobre as autoras}

Alessandra Dilair Formagio Martins (alessandra.formagio@bol.com.br) Doutorado em Educação pela Universidade Metodista de Piracicaba, Brasil (2013) Docente do Centro Universitário Nossa Senhora do Patrocínio, Brasil.

Maria Inês Bacellar Monteiro (monteirobim@gmail.com)

Doutorado em Psicologia pela Universidade de São Paulo, Brasil (1992). Docente em Tempo Integral do Programa de Pós Graduação em Educação da Universidade Metodista de Piracicaba. 